\title{
Guidelines for Empirical Papers on Group Care Programs
}

\author{
Carl F. Weems
}

Published online: 8 July 2011

(C) Springer Science+Business Media, LLC 2011

The Child and Youth Care Forum (CYCF) publishes a relatively large number of papers on youth served in residential or group care programs (in 2010, almost one-third, or 9 out of 32, of the papers were on group care). Across these papers the content of program description has varied widely. In this issue of CYCF, Lee and Barth note that knowledgebuilding about group care's effectiveness and outcomes has been hindered by a lack of uniformity in the description of a program as well as its goals and outcomes. The basic point they make is simple but very important, and it is that a particular label may not always identify similar programs or intervention models. Residential or other group care programs may differ fundamentally on several levels but often share the same or similar label for widely differing programs, which may promote misunderstanding of the value of an individual program.

Lee and Barth argue that providing clarity for external stakeholders (e.g., parents and youth) is essential and that more comprehensive and standardized program descriptions are needed to improve the research and interpretation of findings on group care programs. Reporting descriptive information about programs consistently will also facilitate systematic reviews by ensuring clearer comparison of the results from research studies. In their paper in this issue, Lee and Barth propose Group Care Reporting Standards, for which such characteristics as program goals, population served, and therapeutic components are detailed explicitly in reports on group care programs for youth. These standards specify the information that should be included in empirical papers that describe group care programs or outcomes of youth served in these programs. Lee and Barth emphasize the importance of transparency with regards to the program's desired outcomes, population, location, size, model or theory of change, activities, staffing, and several other characteristics. This content is to be included in the methods section (or elsewhere as appropriate).

Authors interested in submitting original research that include data from youth receiving group care services should therefore include all of the details noted by Lee and Barth, as relevant, in their manuscripts (See Table 1). Reviews of the literature should also attend to each of these issues (See Lee and Barth, this issue). The idea of reporting standards

C. F. Weems ( ()

Department of Psychology, University of New Orleans, New Orleans, LA 70148, USA

e-mail: cweems@uno.edu 
Table 1 Group care reporting standards

\begin{tabular}{|c|c|}
\hline Characteristic: & What to report: \\
\hline 1. Outcomes & $\begin{array}{l}\text { The primary goal of the group care program and the purpose for which } \\
\text { youth are placed }\end{array}$ \\
\hline 2. Size & Population density of living unit or program \\
\hline 3. Population & $\begin{array}{l}\text { A description of what types of youth are served and proximity to home } \\
\text { communities }\end{array}$ \\
\hline 4. Setting and location & The physical setting of the group care program \\
\hline 5. Program model & $\begin{array}{l}\text { The approach or framework that organizes the interventions and activities } \\
\text { within the relevant setting }(\mathrm{s}) \text {; may be a branded model or articulated } \\
\text { logic model/theory of change }\end{array}$ \\
\hline 6. Practice elements & $\begin{array}{l}\text { Activities within the program that are likely to contribute to desired } \\
\text { outcomes }\end{array}$ \\
\hline 7. Staffing details & $\begin{array}{l}\text { The structure and scheduling of direct care staff as well as relevant } \\
\text { background on their experience and credentials }\end{array}$ \\
\hline 8. Systems influences & $\begin{array}{l}\text { Macro-level forces that provide resources or oversight and accountability } \\
\text { to a group care program }\end{array}$ \\
\hline 9. Restrictiveness & $\begin{array}{l}\text { Standards set in the living environment to meet safety, developmental, or } \\
\text { therapeutic needs }\end{array}$ \\
\hline 10. Design & If the paper evaluates outcomes- describe the evaluation design \\
\hline 10a. Open trial/uncontrolled & $\begin{array}{l}\text { Conform to the Transparent Reporting of Evaluations with } \\
\text { Nonrandomized Designs (TREND) guidelines. Information can be found } \\
\text { at http://www.cdc.gov/trendstatement/ }\end{array}$ \\
\hline 10b. Randomized design & $\begin{array}{l}\text { Conform to the Consolidated Standards of Reporting Trials (CONSORT) } \\
\text { guidelines. Information can be found at } \\
\text { http://www.consort-statement.org/ }\end{array}$ \\
\hline
\end{tabular}

provided by Lee and Barth is derived from reporting standards established for clinical trials. Therefore, in addition to the recommendations in their paper, I have added "Design" to the table of required information. Papers that use an Open Trial/Uncontrolled design should conform to the Transparent Reporting of Evaluations with Nonrandomized Designs (TREND) guidelines (Information can be found at http://www.cdc.gov/trendstatement/). In these studies the design, by its nature, is limited in establishing the efficacy of the intervention. In addition to following the TREND guidelines, authors of noncontrolled studies should include reference to longitudinal findings (or use normative comparisons, reliable change indices) to benchmark the findings reported. Papers should also reference previous studies and the size of the effect produced in the current study as compared to other previous studies using similar outcomes. In this regard Cohen's d (or similar effect size metric) should be reported. Studies reporting a randomized design should conform to the Consolidated Standards of Reporting Trials (CONSORT) guidelines (Information can be found at http://www.consort-statement.org/). All intervention studies (regardless of group care) should report the design and follow either the TREND or CONSORT guidelines.

\section{Reference}

Lee, B. R., \& Barth R. P. (this issue). Defining group care programs: An index of reporting standards. Child and Youth Care Forum. doi:10.1007/s10566-011-9143-9. 